\title{
OSLAM syndrome
}

INSERM

\section{Source}

INSERM. (1999). Orphanet: an online rare disease and orphan drug data base. OSLAM syndrome. ORPHA:2760

OSLAM syndrome is characterised by the association of osteosarcoma, limb anomalies (clinodactyly with brachymesophalangy, bilateral radioulnar synostosis and absence of one digital ray of the foot) and red cell macrocytosis without anaemia. 